\title{
A Review on MPPT Control Methods of Photovoltaic Systems with DC bus
}

\author{
Yan $\mathrm{Li}^{1}$, Shaowu $\mathrm{Li}^{1,}{ }^{*}$, Jingxun Fan ${ }^{1}$, and Xianping $\mathrm{Zhu}^{1}$ \\ ${ }^{1}$ Hubei Minzu University, School of Information Engineering, 44500Enshi, China
}

\begin{abstract}
Maximum point power tracking (MPPT) technology is widely used to improve photovoltaic (PV) output power, and the traditional MPPT control methods are being used more and more widely. However, the PV system controlled by MPPT cannot be directly applied to the direct-current (DC) microgrid, and the output voltage is not stable, resulting in more than the DC bus rated voltage. Based on this problem, some researchers have proposed the control method with DC bus. At present, there are few researches on this control method in the world, the research status and process of this aspect are not discussed in detail. This paper analyzes and summarizes the PV system with DC bus of MPPT control method based on referring to the existing relevant literature, hoping to provide some help for the subsequent research and experiments of relevant researchers.
\end{abstract}

\section{Introduction:}

With the rapid growth of world energy demand, it is important to seek reliable, economically effective, and lasting renewable energy to meet future energy demand. Solar energy is one of the most promising renewable sources of energy available[1-3]. PV system is greatly affected by the external environment (weather conditions and shadows), resulting in low conversion efficiency of PV arrays. The maximum power tracking technology of PV system solves this problem, and the technology is becoming more and more mature. It is widely used in the market[4]. At present, the more mature methods have disturbance method[5], conductance increment method[6], particle swarm optimization[7], fuzzy logic control method[8], neural network method[9]. To improve market competitiveness, many small and medium-sized PV array manufacturers have begun to try to encapsulate small peripheral circuits (including PV cells, DC/DC converters, and maximum power tracking control circuits) in $\mathrm{PV}$ modules. These modules are usually connected to DC busbars, which makes them easier to apply, and DC systems contribute to the connection of PV cells and energy storage devices, and improve the reliability and energy utilization of PV systems. Provide sufficient power for PV system supply equipment[10]. In the process of PV energy grid connection, it is necessary to adjust the DC bus voltage to keep constant. DC bus voltage change is an effective index to judge the input and output power flow state, and the smaller DC bus capacitance, the greater voltage ripple, the lower the MPPT efficiency[11]. As a result, PV system MPPT with DC bus has been widely concerned and applied. From the control method of PV system with DV bus and the impact of the technology on the power grid two aspects are discussed.

\section{Control methods of PV Systems MPPT with DC bus}

In linear circuit, the power supply output can reach the maximum when the load resistance and the internal resistance are the same[12]. Although PV cells are nonlinear, they can be regarded as linearized circuits in a very short time. The power electronic converter with an energy storage system is used to convert the output power of PV panel to achieve impedance matching. The source of renewable energy is being connected to the load and energy storage system through DC/DC converter[13]. $\mathrm{DC} / \mathrm{DC}$ converter is essentially the maximum power tracking controller, by changing the duty cycle to find the maximum power point. 3 different $\mathrm{DC} / \mathrm{DC}$ transform circuits correspond to the following three formulas.

$$
\begin{gathered}
D_{m-\text { boost }}=1-\frac{C}{V_{b u s}} \\
D_{m-\text { buck }}=\frac{V_{b u s}}{C} \\
D_{m-\text { buckboost }}=\frac{V_{\text {bus }}}{C+V_{\text {bus }}}
\end{gathered}
$$

Take the buck circuit principle diagram as an example, as shown in figure 1.

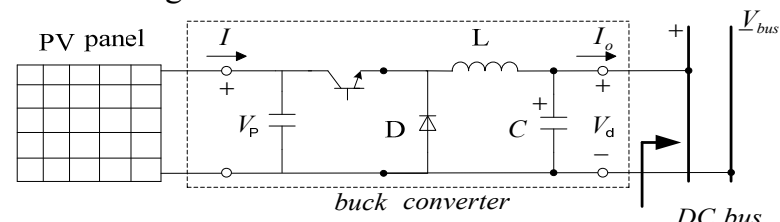

Fig. 1.buck circuit schematic diagram

According to the principle of MPPT control method with DC bus, through consulting and analyzing relevant literature, most of the MPPT control methods with DC bus

*Corresponding author: xidu surfer@163.com 
are mainly by changing the topology of reasonable choice of the components. DC/DC converters are mainly buck, boost to buck/boost circuits, and a few researchers have proposed other converters[14].For example, inductor-capacitor-diode (LCD) circuits[10].

\section{MPPT of control methods on PV systems with DC bus}

\subsection{Incremental conductance (IC) method}

A MPPT technique based on constant duty cycle frequency conversion control is proposed, which uses frequency change and constant duty cycle control to realize power tracking by control programming[15]. The advantage of this method is that the circuit structure is simple, it can provide suitable pulse width, and it can also extract energy from PV array at low sunshine level. Another incremental conductance method is proposed, which is combined with fuzzy controller to adjust the duty cycle. When the I/V reaches the maximum power point, the algorithm returns the working voltage corresponding to the maximum power point at the end of the algorithm[16]. Through the above two incremental conductance methods, choosing the appropriate duty cycle is the key to solve the problem.

\subsection{Perturb and Observe (P\&O) Method}

Based on the traditional P\&O, a PI controller is added. The principle is that reduce the power-voltage curve to zero using PI-based P\&O closed-loop control[17]. The circuit is similar to the adaptive integrated circuit. The fluctuation of output voltage on PV is the violent fluctuation of DC bus. A new P\&O method is proposed. The first traditional current instruction tracking MPPT method is used to adjust the step size in the light of the change rate of DC bus voltage. Besides, the lower voltage limit protection is added to avert DC bus voltage collapse[18]. The P\&O method based on digital signal processing (DSP) system is sampled by peak current control, instantaneous value and small disturbance value to replace the average value[19].

\subsection{Other control methods}

Particle swarm optimization (PSO) periodically scans the power-voltage curves of each PV array. A proportional speed index algorithm with reduced speed shift improves, unifying the MPPT and DC bus voltage regulation under the same control to maximize the global and constraint of $\mathrm{DC}$ bus power operation. A two-way DC/DC converter is installed on the DC bus which is connected in series with the output supply from the storage device to the storage device[20]. PV system needs constant voltage control. Fuzzy logic controller (FLC) is used to maintain a constant DC bus voltage buck converter. The design of FLC is relatively simple and does not need to understand a very accurate model. It is a fast controller in the over-state. The signal is smoother and less fluctuating in the steady-state, combined with the pollen teaching algorithm[21]. The optimal working current is proportional to the short circuit, and the MPPT is realized by detecting the short circuit current. Estimation of optimal operating current using intermittent short current pulses[22].

\section{Effect of PV MPPT with DC bus control method on power grid.}

\subsection{Effect of PV MPPT with DC bus control method on system stability}

When operating in isolated island mode, the microgrid will be disconnected from the power grid. Most PV system MPPT control methods cannot make PV power supply work stably in isolated island microgrid. At this time, PV cells must be connected to DC bus voltage to improve voltage regulation ability, so the demand for DC bus MPPT control strategy is increasing[23]. Because the output power of $\mathrm{PV}$ system is proportional to the current injected into the grid, when the current of the grid is unstable, the output power of the PV system will change arbitrarily. To solve this problem, the maximum power output can be controlled by adjusting the DC bus voltage, thus improving the stability of the system. Concrete method: the DC bus voltage adjusts the amplitude of the microgrid current by using the proportional-integral voltage controller, controls the DC voltage bus voltage at about $200 \mathrm{~V}$, then adjusts the amplitude of the injected power network current according to the DC bus voltage value, and finally improves the stability of the system[24].

\subsection{Effect of PV MPPT with DC bus control methods on power quality}

Because the input power of PV system has been changing, there will be large DC voltage fluctuation on the DC bus, which leads to the MPPT method of PV system cannot better track the maximum power point. Lead to a large amount of power waste and power quality decline. A MPPT control method with DC bus type can solve the root cause[25]. Aiming at this problem, the PWM inverter is used and controlled to realize the stability of DC bus voltage regulation at the input end of the inverter, thus improving the robustness and high energy quality of the power injected into the power grid.

\subsection{Effect of PV MPPT with DC bus control methods on cost}

Due to regional differences, solar resource distribution and its imbalance, modular PV distributed strategy is the solution to this problem. The modular PV system operates in a variety of modes, which are mainly identified according to different DC bus voltage levels, and DC bus is used as an information carrier[26]. By changing the DC bus voltage and without adding additional communication links, the switching of different modes and the 
corresponding change of converter control mode can be realized. Multiple PV boards are directly connected to the common DC bus by a parallel power converter, and through DC bus can expand a variety of loads, as shown in figure 2. This greatly reduces the cost of PV systems and improves reliability[26].

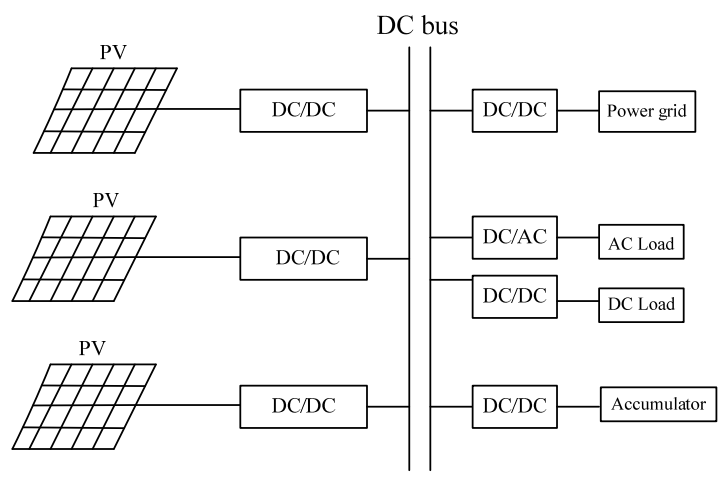

Fig. 2. DC bus connection diagram

\section{Conclusions}

Because the DC bus PV system is greatly affected by environmental changes, the maximum power tracking control of the photovoltaic array is a complex and comprehensive problem. To solve this problem, researchers have come up with a variety of solutions, but advantages and disadvantages coexist. Based on the original scheme, the researchers put forward a more perfect scheme to improve the topology of the DC/DC converter, and the effectiveness of the method is verified and compared by simulation. With the vigorous development of solar energy resource utilization, the realization method on MPPT of PV system with DC bus will become more and more mature.

\section{Acknowledgements}

This work is supported by the National Natural Science Foundation of China under Grant No.61963014.

\section{References}

1. Yuan L, Cui X. Study on maximum power point tracking for photovoltaic power generation system $[\mathrm{J}]$. IEEE.

2. Lewis N, Nocera D. Powering the planet: Chemical challenges in solar energy utilization[J]. Proceedings of the National Academy of Sciences of the United States of America.

3. Org Z. A review of solar photovoltaic technologies $[\mathrm{J}]$.

4. Esram T, Chapman P L. Comparison of Photovoltaic Array Maximum Power Point Tracking Techniques[J]. IEEE Transactions on Energy Conversion, 2007, 22(2): 439-449.
5. Chen Y, Smedley K M. A cost-effective single-stage inverter with maximum power point tracking $[\mathrm{J}]$. IEEE Transactions on Power Electronics, 2004, 19(5): 1289-1294.

6. Wang Y, Ren B. Fault Ride-Through Enhancement for Grid-Tied PV Systems With Robust Control[J]. IEEE Transactions on Industrial Electronics, 2018, 65(3): 2302-2312.

7. Safari A, Mekhilef S. Simulation and Hardware Implementation of Incremental Conductance MPPT With Direct Control Method Using Cuk Converter[J]. IEEE Transactions on Industrial Electronics, 2011, 58(4): 1154-1161..

8. Pachauri R K, Chauhan Y K. Fuzzy Logic Controlled MPPT Assisted PV-FC Power Generation for Motor Driven Water Pumping System[M]. New York: IEEE, 2014.

9. Li S W. A MPPT control strategy with variable weather parameter and no DC/DC converter for photovoltaic systems[J]. Solar Energy, 2014, 108: 117-125.

10. Chattopadhyay S K, Chakraborty C, Pal B C, et al.: Cascaded H-Bridge \& Neutral Point Clamped Hybrid Asymmetric Multilevel Inverter Topology for Grid Interactive Transformerless Photovoltaic Power Plant, 38th Annual Conference on IEEE Industrial Electronics Society, New York: Ieee, 2012: 5074-5079.

11. Zeng J W, Zuo M X, Cheng H, et al.: Power Pulsation Decoupling for a Two-Stage Single-Phase Photovoltaic Inverter with Film Capacitor, 2017 IEEE Energy Conversion Congress and Exposition, New York: IEEE, 2017: 468-474.

12. Joshi P, Arora S. Maximum power point tracking methodologies for solar PV systems - A review[J]. Renewable \& Sustainable Energy Reviews, 2017, 70: 1154-1177.

13. Zhang N, Sutanto D, Muttaqi K M. A review of topologies of three-port DC-DC converters for the integration of renewable energy and energy storage system $[\mathrm{J}]$. Renewable \& Sustainable Energy Reviews, 2016, 56: 388-401.

14. Li S W, Attou A, Yang Y C, et al. A maximum power point tracking control strategy with variable weather parameters for photovoltaic systems with DC bus[J]. Renewable Energy, 2015, 74: 478-488.

15. Hsieh G C, Chen H L, Chen Y, et al.: Variable frequency controlled incremental conductance derived MPPT photovoltaic stand-along DC bus system, Apec 2008: Twenty-Third Annual IEEE Applied Power Electronics Conference and Exposition, Vols 1-4, New York: IEEE, 2008: 1849.

16. De Brito M a G, Galotto L, Sampaio L P, et al. Evaluation of the Main MPPT Techniques for Photovoltaic Applications[J]. IEEE Transactions on Industrial Electronics, 2013, 60(3): 1156-1167.

17. Liu F, Zhou Y, Yin J, et al.: An improved MPPT arithmetic and grid-connected control strategy for 
single-stage three-phase PV converter with LCL filter, Iciea 2008: 3rd IEEE Conference on Industrial Electronics and Applications, Proceedings, Vols 1-3, New York: IEEE, 2008: 808-813.

18. Liu X, Lopes L. An improved perturbation and observation maximum power point tracking algorithm for PV arrays[C]. IEEE Power Electronics Specialists Conference, 2004.

19. Renaudineau H, Donatantonio F, Fontchastagner J, et al. A PSO-Based Global MPPT Technique for Distributed PV Power Generation[J]. IEEE Transactions on Industrial Electronics, 2015, 62(2): 1047-1058.

20. Nansur A R, Hermawan A S L, Murdianto F D. Constant Voltage Control Using Fuzzy Logic Controller (FLC) to Overcome The Unstable Output Voltage of MPPT in DC Microgrid System[M]. New York: IEEE, 2018: 19-24.

21. Hamzaoui I, Bouchafaa F, Hadjammar A: Investigation of the behavior of a three phase grid-connected photovoltaic system to control active and reactive power with DPC, Salame C, Elcharif H, Hassan F E, Eltahchi M, editor, Impact of Integrated Clean Energy on the Future of the Mediterranean
Environment, Amsterdam: Elsevier Science Bv, 2011: 493-502.

22. Noguchi T, Togashi S, Nakamoto R. Short-current pulse based adaptive maximum-power-point tracking for photovoltaic power generation system[J]. Electrical Engineering in Japan, 2002, 139(1): 65-72.

23. Cai H D, Xiang J, Wei W. Decentralized Coordination Control of Multiple Photovoltaic Sources for DC Bus Voltage Regulating and Power Sharing $[\mathrm{J}]$. IEEE Transactions on Industrial Electronics, 2018, 65(7): 5601-5610.

24. Xia Y H, Yu M, Yang P C, et al. Generation-Storage Coordination for Islanded DC Microgrids Dominated by PV Generators[J]. IEEE Transactions on Energy Conversion, 2019, 34(1): 130-138.

25. Chen Y M, Cheng C S, Wu H C. Grid-connected hybrid $\mathrm{PV} /$ wind power generation system with improved DC bus voltage regulation strategy[C]. IEEE, 2006.

26. Sun K, Zhang L, Xing Y, et al. A Distributed Control Strategy Based on DC Bus Signaling for Modular Photovoltaic Generation Systems With Battery Energy Storage [J]. IEEE Transactions on Power Electronics, 2011, 26(10): 3032-3045. 